\title{
Analisis Pengembangan Budidaya Rumput Laut (Euchema cottoni) di Perairan Kosiwo Kabupaten Yapen
}

\author{
Analysis of the Cultivation Development of Seaweed (Euchema cottoni) in \\ Kosiwo District, Yapen Regency
}

\author{
Richard Y. Mambai ${ }^{1}$, Suryawati Salam², Erni Indrawati ${ }^{3}$ \\ ${ }^{1}$ Dinas Perikanan Kabupaten Yapen Provinsi Papua \\ 2Program Studi Agribisis Fakultas Pertanian Universitas Bosowa \\ ${ }^{3}$ Program Studi Budidaya Perairan Program Pascasarjana Universitas Bosowa \\ E-mail: mbi.richardjohnny@gmail.com
}

Diterima: 30 Januari 2020/Disetujui 05 Juni 2020

\begin{abstract}
Abstrak. Rumput laut merupakan salah satu komoditas budidaya laut yang memiliki nilai ekonomis tinggi. Upaya mengembangkan budidaya rumput laut diperlukan untuk meningkatkan produksi serta meningkatkan pendapatan masyarakat pesisir. Keberhasilan budidaya rumput laut sangat dipengaruhi oleh faktor kualitas perairan yang mendukung dan sesuai untuk pertumbuhannya. Penelitian ini bertujuan menganalisis lingkungan internal dan eksternal yang mempengaruhi budidaya dan mengkaji strategi yang tepat dalam usaha pengembangan budidaya rumput laut (Eucheuma cottonii) di perairan distrik Kosiwo Kabupaten Kepulauan Yapen. Metode yang digunakan adalah analisis data eksternal dan internal yang di analisis SWOT melalui tiga tahap analisis yaitu tahap pengumpulan data, tahap analisis dan tahap pengambilan keputusan. Hasil penelitian menunjukkan lingkungan internal yang mempengaruhi perkembangan budidaya rumput laut di distrik Kosiwo adalah produksi; manajeman dan pendanaan; sumber daya manusia; investasi dan lokasi budidaya. Lingkungan eksternal yang mempengaruhi perkembangan usaha budidaya rumput laut di Distrik Kosiwo adalah ekonomi, sosial budaya dan lingkungan; pasar; pesaing; IPTEK serta iklim dan cuaca. Strategi yang dapat digunakan mengadakan pelatihan tentang budidaya, penanganan penyakit dan pengolahan produk turunan untuk meningkatkan keterampilan pembudidaya sehingga mampu menghasilkan produk dan memanfaatkan lahan budidaya untuk menghasilkan rumput laut dalam jumlah besar agar mampu memperluas jaringan pemasaran
\end{abstract}

Kata Kunci: Euchema Cottoni, Budidaya Perairan, Analisis Pengembangan, Yapen

\begin{abstract}
Seaweed is one of the marine cultivation commodities which has high economic value. Efforts to develop seaweed cultivation are needed to increase the production and the income of coastal communities. The success of seaweed cultivation is strongly influenced by the water quality factors that support and are suitable for its growth. This study aims to analyze the internal and external environment that affect cultivation and to assess appropriate strategies in the development of seaweed (Eucheuma cottonii) cultivation in the coastal area of Kosiwo district, Kepulauan Yapen Regency. The method used is external and internal data analysis, which is SWOT analysis through three stages of analysis, namely the data collection stage, the analysis stage and the decision-making stage. The results showed that the internal environment that affects the development of seaweed cultivation in Kosiwo district is production; management and funding; human Resources; investment and cultivation locations. The external environment that affects the development of seaweed farming in Kosiwo District is the economy, socio-culture and environment; market; competitor; Science and technology and climate and weather. Strategies that can be used are to hold a training on cultivation, disease and processing management of derivative products to improve the skills of cultivators so that they are able to produce products and utilize cultivated land to produce seaweed in large quantities in order to be able to expand the marketing network.
\end{abstract}

Keywords: Euchema Cottoni, Aquaculture, Developmnet Analysis, Yapen

\section{Pendahuluan}

Indonesia merupakan negara maritim dengan potensi perikanan yang sangat besar. Sekitar dua per tiga dari luas wilayah Indonesia merupakan laut, dengan cakupan area mencapai sekitar 5.8 juta, yang dibatasi oleh garis pantai sepanjang $95.18 \mathrm{~km}$ dan mengelilingi lebih dari 18.000 pulau. Keadaan geografis yang baik disertai dengan Indonesia yang beriklim tropis menghasilkan keanekaragaman dan produktivitas biota laut yang tinggi (Tarigan, 2015).

Salah satu sumber daya hayati laut Indonesia yang potensial adalah rumput laut. Perairan yang kaya akan mineral dan sinar matahari yang dimiliki Indonesia merupakan lahan subur untuk pertumbuhan rumput laut. Sebagai negara kepulauan yang memiliki potensi pengembangan rumput laut ini seyogyanya Indonesia menjadi produsen utama komoditas rumput laut di pasar 
dunia. Areal strategis yang dapat digunakan untuk budidaya rumput laut di seluruh Indonesia meliputi wilayah seluas \pm 1.380.931 ha. Potensi daerah sebaran rumput laut di Indonesia sangat luas, baik yang tumbuh secara alami maupun yang dibudidayakan. Tersebar hampir di seluruh wilayah seperti Sumatera, Jawa, Bali, Nusa Tenggara, Kalimantan, Sulawesi, Maluku, dan Papua (Anggadiredja, 2008 dalam Hidayati, 2009).

Rumput laut merupakan salah satu komoditas budidaya laut yang memiliki nilai ekonomis tinggi. Pemanfaatan rumput laut yang semakin beragam baik dalam industri makanan, minuman, kosmetik maupun obatobatan menyebabkan kebutuhannya semakin meningkat. Menurut Atmadja et al. (1996), pada awal 1980 perkembangan permintaan rumput laut di dunia meningkat seiring dengan peningkatan pemakaian rumput laut untuk berbagai keperluan antara lain di bidang industri, makanan, tekstil, kertas, cat, kosmetika, dan farmasi (obat-obatan).

Eucheuma cottonii atau Kappaphycus alvarezii adalah jenis rumput laut yang banyak dibudidaya- kan di negara Asia Pasifik termasuk Indonesia. Indonesia telah meningkatkan produksi jenis ini dari 25.000 ton pada tahun 2001 menjadi 55.000 ton pada tahun 2004 (McHugh, 2006). Kappaphycus menghasilkan karaginan jenis kappa yang dapat dimanfaatkan untuk industri makanan, kosmetik, obat-obatan, tekstil, dan sebagai materi dasar aromatic diffuser (Chapman dalam Aslan, 1991). Faktor utama keberhasilan kegiatan budidaya rumput laut adalah pemilihan lokasi yang tepat. Penentuan lokasi dan kondisi perairan harus disesuaikan dengan metode budidaya yang akan digunakan. Tumbuhan laut termasuk makroalga atau rumput laut berinteraksi dengan lingkungan fisika kimianya. Di antara faktor lingkungan tersebut adalah ketersediaan cahaya, suhu, salinitas, arus dan ketesediaan nutrien (Lobban \& Harrison, 1997). Oleh karena itu faktor fisika kimia perairan menjadi salah satu penentu keberhasilan budidaya rumput laut.

Rumput laut (Eucheuma cottonii) mulai dikembangkan di kabupaten Yapen sejak awal 2000 dan mencapai produksi 100 ton pada tahun 2008 dimana konsentrasi pengembangan masih berada pada kampung Sarawandori, Kosiwo dan distrik Ansus. Potensi yang dapat diprediksi pada tiga daerah tersebut mencapai 500 ton bila dilakukan pengembangan secara serius oleh seluruh stakeholder di kepulauanYapen tersebut. Berdasarkan potensi areal, luas perairan teluk Kosiwo secara keseluruhan adalah 7.568,51 hektar, dengan potensi lahan pengembangannya mencapai $1.605,74$ hektar. Potensi tersebut diperoleh dengan memperhitungkan kondisi perairan dan kesesuaian perairan untuk budidaya rumput laut. Potensi yang baru dimanfaatkan seluas 929,9 Ha, dengan melibatkan 1.125 pembudidaya dari 125 kelompok pembudidaya. Pembudidaya rumput laut yang sudah ada kurang berorientasi pada penanganan pasca panen dan pengolahan, sehingga hasil panen tidak mampu memberi nilai tambah produk.

Analisis untuk pengembangan rumput laut di Kabupaten Kepulauan Yapen sangat perlu untuk dilakukan mengingat besarnya potensi dan lahan yang dimiliki dengan perkiraan produksi yang cukup besar. Pengembangan budidaya memerlukan dukungan teknologi (Yunus et al,. 2019), kelayakan lokasi (Indriyani et a.
2019), faktor oseanografi (Bolqiah et al., 2019; Ridwan et al., 2019)) dan pengembangan manajemen spesiesnya (Budi et., 2016; Budi et., 2018). Dengan wilayah perairan yang luas dan strategis serta memiliki potensi sumber daya perairan yang cukup besar, akan mengoptimalkan pengelolaan potensi sumber daya kawasan pesisir teluk Kosiwo untuk kegiatan budidaya rumput laut belum termanfaatkan.

Tujuan penelitian untuk menganalisis lingkungan internal dan eksternal dalam menyusun strategi untuk pengembangan budidaya rumput laut (Eucheuma cottonii) di perairan distrik KosiwoKabupaten Kepulauan Yapen.

\section{Metode Penelitian}

a. Jenis Penelitian

Penelitian ini merupakan jenis penelitian deskriptif kuantitatif. Kajian yang dilakukan dengan menggunakan kasus pada usaha budidaya rumput laut di Perairan Teluk Sarawandori Distrik Kosiwo Yapen Papua

b. Lokasi Penelitian

Penelitian ini dilakukan di daerah budidaya rumput laut Teluk Kosiwo yang merupakan salah satu daerah pesisir Kabupaten Kepulauan Yapen.

c. Jenis dan Sumber Data

Jenis dan sumber data penelitian merupakan faktor yang penting yang menjadi pertimbangan yang menentukan metode pengumpulan data. berdasarkan pada pengelompokannya yaitu:

- Data primer merupakan sumber data penelitian yang diperoleh secara langsung dari sumber asli (tidak melalui perantara). Data primer secara khusus dikumpulkan oleh peneliti untuk menjawab pertanyaan penelitian (Indriantoro, 2009).

- Data sekunder merupakan sumber data penelitian yang diperoleh peneliti secara tidak langsung melalui media perantara atau diperoleh dan dicatat oleh pihak lain (Indriantoro, 2009). Dalam penelitian ini data diperoleh dari BPS maupun instansi terkait.

d. Teknik Pengumpulan Data

Metode pengumpulan data dalam penelitian ini dilakukan melalui:

- Wawancara, yakni teknik pengumpulan data dengan cara mengadakan tanya jawab secara lisan terhadap responden,

- Kuesioner, yakni suatu teknik pengumpulan data dengan cara memberikan secara tertulis beberapa pertanyaan yang harus dijawab oleh petani budidaya rumput laut sebagai responden.

Tabel 1 Jumlah Penduduk di Distrik Kosiwo Berdasarkan Umur dan Kelamin, 2018

\begin{tabular}{ccccc}
\hline Kelompok & \multicolumn{2}{c}{ Jenis Kelamin } & \multirow{2}{*}{ Jumlah } & $\begin{array}{c}\text { Persentase } \\
(\%)\end{array}$ \\
\cline { 2 - 3 } Umur & Laki-laki & Perempuan & & 1397 \\
\hline $0-14$ & 703 & 694 & 32 \\
$15-64$ & 1446 & 1357 & 2803 & 64,3 \\
$>64$ & 78 & 84 & 162 & 3,7 \\
\hline
\end{tabular}

Sumber: BPS Kabupaten Yapen, 2018 
e. Teknik Analisis Data

- Faktor-faktor internal dan eksternal yang didapatkan dari identifikasi yaitu faktor kekuatan, kelemahan, peluang dan ancaman kemudian dimasukkan ke dalam matrik SWOT untuk dianalisis (Rangkuti,2009). Analisis SWOT ini menggambarkan secara jelas peluang dan ancaman eksternal yang dihadapi petani, yang disesuaikan dengan kekuatan dan kelemahan yang dimiliki. Matrik ini akan menghasilkan 4 set kemungkinan strategi antara lain strategi SO, strategi ST, strategi WO, dan strategi WT.

- Menyilangkan masing-masing faktor sehingga didapat strategi SO, ST, WO, dan strategi WT.

- Memilih strategi yang sesuai dengan kuadran I, II, III, DAN IV.

\section{Hasil dan Pembahasan}

Lahan berperan penting sebagai tempat terlaksananya kegiatan usahatani rumput laut untuk menghasilkan produksi yang ingin dicapai. Luas lahan merupakan salah satu faktor penentu berjalan atau tidaknya usahatani rumput laut. Luas lahan yang dimaksud dalam penelitian ini adalah luas wilayah permukaan laut yang digunakan sebagai lahan usahatani rumput laut.

Tabel 2 Luas Lahan Budidaya di Distrik Kosiwo Kabupaten Yapen

\begin{tabular}{ccc}
\hline \multirow{2}{*}{ Kategori } & \multicolumn{2}{c}{ Responden } \\
\cline { 2 - 3 } & Petani rumput laut & Persentase \\
\hline$<0,5$ ha & - & - \\
$0,5-2$ ha & 9 & 23.68 \\
$>2$ ha & 29 & 76.32 \\
\hline Total & 38 & 100 \\
\hline Sumber: Data Primer, 2018 & &
\end{tabular}

Jumlah produksi rumput laut di Distrik Kosiwo Kabupaten Yapen cukup bervariasi di tingkat pembudidaya. Berikut nilai produksi rumput laut di Distrik Kosiwo Kabupaten Yapen.

Tabel 3 Rata-Rata Produksi Rumput Laut di Distrik Kosiwo Kabupaten Yapen

\begin{tabular}{clcc}
\hline No. & Produksi & Jumlah Petani & Persentase \\
\hline 1 & $100-200$ & 14 & 36.84 \\
2 & $201-300$ & 13 & 34.21 \\
3 & $301-400$ & 6 & 15.78 \\
4 & $>400$ & 5 & 13.15 \\
\hline Jumlah & 38 & 100 \\
\hline
\end{tabular}

Sumber: Data primer 2018

Jumlah produksi yang terbanyak diperoleh responden sekitar 100-200 kg yaitu 14 orang $(36,84 \%)$, sedangkan yang paling sedikit jumlah produksinya diperoleh responden $>401 \mathrm{~kg}$ yaitu 5 orang $(13,15 \%)$. Perbedaan jumlah produksi yang diperoleh disebabkan oleh perbedaan jumlah tali riis yang dipakai dalam usaha rumput laut dan kemampuan pembudidaya yang berbeda-beda dalam operasionalnya.

Lingkungan internal berupa kekuatan yang mempengaruhi perkembangan budidaya rumput laut di distrik Kosiwo adalah produksi yang dihasilkan memiliki kualitas yang baik oenggunaan modal yang efektif, lokasi yang baik dan ketersedian sumberdaya manusia yang memadai.

Tabel 4 Matriks faktor internal strength

\begin{tabular}{|c|c|c|c|c|c|}
\hline Kmponen & Strength & $\mathrm{Bbt}$ & Ratng & $\mathrm{Skr}$ & Rnk \\
\hline Produk (40\%) & $\begin{array}{l}\text { Produk yang dihasilkan } \\
\text { berkualitas baik }\end{array}$ & 0.40 & 4 & 1.60 & 1 \\
\hline $\begin{array}{l}\text { Manjemen \& } \\
\text { pendanaan }(15 \%)\end{array}$ & $\begin{array}{l}\text { Penggunan modal yang } \\
\text { efektif }\end{array}$ & 0.15 & 3 & 0.45 & 4 \\
\hline $\operatorname{SDM}(15 \%)$ & Banyaknya tenaga kerja & 0.15 & 4 & 0.60 & 3 \\
\hline Investasi $(10 \%)$ & $\begin{array}{l}\text { Sarana dan fasilitas } \\
\text { Invst. bdya mdh didapat }\end{array}$ & 0.10 & 3 & 0.30 & 5 \\
\hline \multirow[t]{2}{*}{ Lokasi $(20 \%)$} & $\begin{array}{l}\text { Potensi lahan Bdy yg } \\
\text { masih luas }\end{array}$ & 0.20 & 4 & 0.80 & 2 \\
\hline & Total & 1.00 & & 3.75 & \\
\hline
\end{tabular}

Sumber: Data primer 2018

Lingkungan eksternal berupa kelemahan yang mempengaruhi perkembangan usaha budidaya rumput laut di Distrik Kosiwo adalah ekonomi produksi yang belum optimal, terbatasnya modal dan pembudidaya kurang inovatif. Selanjutnya dapat dilihat pada tabel 5 berikut.

Tabel 5 Matriks faktor internal weakness

\begin{tabular}{|c|c|c|c|c|c|c|}
\hline Komponen & Strengtl & & $\mathrm{Bbt}$ & Ratng & Skr & Rnk \\
\hline $\begin{array}{l}\text { Produk } \\
(20 \%)\end{array}$ & $\begin{array}{l}\text { Produksi yang } \\
\text { optimal }\end{array}$ & belum & 0.20 & 2 & 0.40 & 3 \\
\hline $\begin{array}{l}\text { Manajemen } \\
\& \text { pendanaan } \\
(40 \%)\end{array}$ & $\begin{array}{l}\text { Terbatasnya } \\
\text { nyang dimiliki }\end{array}$ & modal & 0.40 & 2 & 0.801 & 1 \\
\hline $\operatorname{SDM}(25 \%)$ & $\begin{array}{l}\text { Pembudidaya } \\
\text { inovatif }\end{array}$ & kurang & 0.25 & 2 & 0.50 & 2 \\
\hline $\begin{array}{l}\text { Investasi } \\
(10 \%)\end{array}$ & $\begin{array}{l}\text { Sarana dan fasil } \\
\text { Investasi yang } n \\
\text { Rusak }\end{array}$ & $\begin{array}{l}\text { tas } \\
\text { nudah }\end{array}$ & 0.10 & 3 & 0.30 & 4 \\
\hline Lokasi (5\%) & $\begin{array}{l}\text { Sulitnya menjan } \\
\text { Lokasi budidaya }\end{array}$ & gkau & 0.05 & 3 & 0.15 & 5 \\
\hline
\end{tabular}

Sumber: Hasil Analisis, 2019

Lingkungan internal pada aspek peluang yang mempengaruhi perkembangan budidaya rumput laut di distrik Kosiwo adalah pertumbuhan masyarakat dan ekonomi yag semakin besar, pasar yang semakin terbuka dan penggunaan teknologi yang semakin berkembang.

Tabel 6. Matriks faktor internal opportunities

\begin{tabular}{|c|c|c|c|c|c|}
\hline Komponen & Strength & Bobot & Rating & Skor & Rank \\
\hline $\begin{array}{l}\text { Sosial, } \\
\text { ekonomi } \\
\text { budaya \& } \\
\text { lingkunagn } \\
(10 \%)\end{array}$ & $\begin{array}{l}\text { Pertumbuhan } \\
\text { penduduk dan } \\
\text { \&kebutuhan } \\
\text { masyarakat } \\
\text { semakin meningkat }\end{array}$ & 0.10 & 3 & 0.30 & 5 \\
\hline Pasar $(25 \%)$ & $\begin{array}{l}\text { Peluang pasar yang } \\
\text { masih uas }\end{array}$ & 0.25 & 3 & 0.75 & 1 \\
\hline $\begin{array}{l}\text { Pesaing } \\
(20 \%)\end{array}$ & $\begin{array}{l}\text { Pembudidaya saingan } \\
\text { yang sedikit }\end{array}$ & 0.20 & 3 & 0.60 & 2 \\
\hline $\begin{array}{l}\text { IPTEK } \\
(20 \%)\end{array}$ & $\begin{array}{l}\text { Penggunaan } \\
\text { teknologi } \\
\text { alamiah }\end{array}$ & 0.20 & 2 & 0.40 & 4 \\
\hline \multicolumn{6}{|c|}{$\begin{array}{c}\text { Cuaca }(25 \%) \text { Baik meningkatkan } \\
\text { hasil panen }\end{array}$} \\
\hline & Total & 1.00 & & 2.55 & \\
\hline
\end{tabular}

Sumber: Hasil Analisis, 2019 
Lingkungan eksternal yang mempengaruhi perkembangan usaha budidaya rumput laut di Distrik Kosiwo adalah ekonomi, sosial budaya dan lingkungan; pasar; pesaing; IPTEK serta iklim dan cuaca. Peluang pasar yang masih luas diharapkan mampu meningkatkan usaha budidaya rumput laut.

Tabel 7 Matriks faktor eksternal threat

\begin{tabular}{|c|c|c|c|c|c|}
\hline Komponen & Strength & Bobot & Rating & Skor & Rank \\
\hline $\begin{array}{l}\text { Sosial, } \\
\text { ekonomi } \\
\text { budaya \& } \\
\text { lingkunagn } \\
(10 \%)\end{array}$ & $\begin{array}{l}\text { Pertumbuhan } \\
\text { penduduk dan } \\
\text { kebutuhan masyarakat } \\
\text { semakin meningkat }\end{array}$ & 0.10 & 2 & 0.20 & 5 \\
\hline $\begin{array}{l}\text { Pasar } \\
(30 \%)\end{array}$ & $\begin{array}{l}\text { Peluang pasar yang } \\
\text { masih luas }\end{array}$ & 0.30 & 2 & 0.60 & 1 \\
\hline $\begin{array}{l}\text { Pesaing } \\
(15 \%)\end{array}$ & $\begin{array}{l}\text { Pembudidaya saingan } \\
\text { yang sedikit }\end{array}$ & 0.15 & 3 & 0.45 & 3 \\
\hline $\begin{array}{l}\text { IPTEK } \\
(20 \%)\end{array}$ & $\begin{array}{l}\text { Penggunaan teknologi } \\
\text { yang alamiah }\end{array}$ & 0.20 & 2 & 0.40 & 4 \\
\hline $\begin{array}{l}\text { Iklim dan } \\
\text { Cuaca } \\
(25 \%)\end{array}$ & $\begin{array}{l}\text { Cuaca dan iklim yang } \\
\text { Baik meningkatkan } \\
\text { hasil panen }\end{array}$ & 0.25 & 2 & 0.50 & 2 \\
\hline & Total & 1.00 & & 2.15 & \\
\hline
\end{tabular}

Sumber: Hasil Analisis, 2019

Sejalan dengan itu, pembudidaya rumput laut pesaing yang masih sedikit menjadi kunci keberhasilan pembudidaya untuk memenangkan persaingan yang ada. Di sisi lain, ketergantungan pembudidaya menjual rumput laut kering kepada satu pedagang pengumpul yang ada di Distrik Kosiwo serta kurangnya minat konsumen terhadap rumput laut di dalam provinsi sangatmengancam keberhasilan usaha ini. Budidaya rumput laut sangat tergantung pada iklim dan cuaca. Cuaca dan iklim dengan curah hujan tinggidiikuti dengan angin kencang sangat merugikan pembudidaya, karena rumput laut akan patah atau ikatan tali akan terlepas sehingga rumput laut banyak hilang.

Berdasarkan total skor faktor-faktor internal dan eksternal budidaya rumput laut, maka dapat dibuat diagram matriks I-E yaitu dengan mencari titik potong sumbu $X$ dan sumbu $\mathrm{Y}$ dengan menghitung selisih masing-masing nilai faktor internal dan faktor eksternal. Titik potong sumbu $X$ (sumbu $\mathrm{W}-\mathrm{S}$ ) diperoleh dari selisih antara total faktor kekuatan dan kelemahan yaitu 1,6 dan titik potong sumbu $\mathrm{Y}($ sumbu $\mathrm{O}-\mathrm{T}$ )) diperoleh dari selisih antara total faktor peluang dan ancaman yaitu 0,40 . Diagram internal ekstenal (I-E) dapat dilihat pada Gambar berikut.

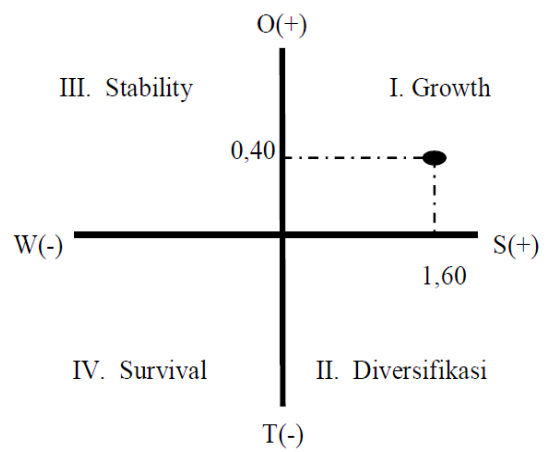

Gambar 1 Diagram SWOT Usaha Budidaya Rumput Laut
Berdasarkan diagram I-E tampak bahwa, usaha budidaya rumput laut di Distrik Kosiwo berada pada kuadran I atau dalam kondisi pertumbuhan. Kuadran I merupakan situasi yang sangat menguntungkan, baik dalam penjualan, produksi, pendapatan atau kombinasi dari ketiganya. Oleh karena itu, usaha budidaya rumput laut ini layak untuk dikembangkan.

\section{Kesimpulan}

Kesimpulan penelitian ini adalah pengembangan dan keberlanjutan usaha budidaya rumput laut di kepulauan Distrik Kosiwo Kabupaten Yapen dapat dilakukan melalui mengadakan pelatihan tentang budidaya, penanganan penyakit dan pengolahan produk turunan untuk meningkatkan keterampilan pembudidaya sehingga mampu berinovasi dalam menghasilkan produk untuk meningkatkan minat konsumen di dalam provinsi dan memanfaatkan lahan budidaya yang masih luas untuk menghasilkan rumput laut dalam jumlah besar agar mampu memperluas jaringan pemasaran,

\section{Daftar Pustaka}

Aslan, L.M. 1991. Budidaya Rumput Laut. Penerbit Kanisius, Yogyakarta.

Atmadja WS. 1996. Pengenalan Jenis Algae Merah. Dalam: Pengenalan Jenis- Jenis Rumput Laut Indonesia. Jakarta. Pusat Penelitian dan Pengembangan Oseanologi, Lembaga Ilmu Pengetahuan Indonesia.

Bolqiah, S. (2019). Hubungan Faktor Oseanografi Terhadap Pertumbuhan Rumput Laut Dengan Metode Rakit Jaring Apung Di Perairan Lakorua Kecamatan Mawasangka Tengah Kabupaten Buton Tengah. Jurnal Sapa Laut (Jurnal Ilmu Kelautan), 3(1).

Budi, S., Karim, M. Y., Trijuno, D. D., Nessa, M. N., Gunarto, G., \& Herlinah, H. (2016). The use of fatty acid omega-3 HUFA and ecdyson hormone to improve of larval stage indeks and survival rate of mud crab Scylla olivacea. Simposium Nasional Kelautan dan Perikanan, 3, 487-498.

Budi, S., Karim, M. Y., Trijuno, D. D., Nessa, M. N., \& Herlinah, H. (2018). Pengaruh Hormon Ecdyson Terhadap Sintasan Dan Periode Moulting Pada Larva Kepiting Bakau Scylla olivacea. Jurnal Riset Akuakultur, 12(4), 335-339.

Hidayati, W. (2009). Analisis Struktur, Perilaku Dan Keragaan Pasar Rumput Laut Eucheuma Cottoni : Kasus Di Kecamatan Mangarabombang, Kabupaten Takalar, Provinsi Sulawesi Selatan. Institut Pertanian Bogor. Bogor.

Indriyani, S., Mahyuddin, H., \& Indrawati, E. (2019). Analisa Faktor Oseanografi Dalam Mendukung Budidaya Rumput Laut Kappaphycus Alvarezii Di Perairan Pulau Sembilan Kabupaten Sinjai. Journal of Aquaculture and Environment, 2(1), 6-11.

Indriantoro, Nur dan Bambang Supomo. 2009. Metodologi Penelitian Bisnis untuk Akuntansi dan Manajemen. BPFE Universitas Gadjah Mada. Yogyakarta. 
Lobban, C.S. \& P.J. Harrison. 1997. Seaweed Ecology and Physiology. Cambridge Univer- sity Press, Cambridge.

McHugh, D.J. 2006. The Seaweed Industry in the Pacific Islands. ACIAR Working Paper No. 61. Australian Center for International Agri- cultural Reseach, Canberra.

Rangkuti, Freddy. (2009). Analisis SWOT Teknik Membedah Kasus Bisnis. Jakarta : Penerbit PT. Gramedia Pustaka Utama.

Ridwan, M., Tantu, G., \& Zainuddin, H. (2019). Analisis Kualitas Keragenan Rumput Laut Jenis Eucheuma Spinosum Pada Ekosistem Yang Berbeda Di Perairan Tomia, Kabupaten Wakatobi, Provinsi Sulawesi Tenggara. Journal of Aquaculture and Environment, 1(2), 1-7

Tarigan, G.R.B. (2015). Analisis Perkembangan dan Faktor-Faktor Yang Memengaruhi Ekspor Rumput Laut Indonesia Periode 1999-2013. Institut Pertanian Bogor. Bogor.

Yunus, A. R., Budi, S., \& Salam, S. (2019). Analisis Kelayakan Lokasi Budidaya Metode Karamba Jaring Apung Di Perairan Desa Pulau Harapan Sinjai. Journal of Aquaculture and Environment, 2(1). 